\title{
Gold Catalysts for Olefin Hydrogenation
}

\section{TRANSMUTATION OF CATALYTIC PROPERTIES}

\author{
G. C. Bond and P. A. Sermon \\ School of Chemistry, Brunel University, Uxbridge, England
}

\begin{abstract}
Gold catalysts active for the hydrogenation and isomerisation of olefins have been prepared by the thermal decomposition of chloroauric acid supported on silica and alumina. The activity depends critically on the concentration of gold in the catalyst. This article considers the implications of these results and their possible industrial applications.
\end{abstract}

The usefulness of gold depends largely on its chemical stability. This stability arises from its inability to chemisorb even such a reactive molecule as oxygen. The lack of reactivity and the consequent paucity of catalytic activity is believed to be due to the absence of unpaired $d$-electrons, which are possessed in some measure by all those metals renowned for their catalytic powers. Thus no dissociation of hydrogen molecules to give adsorbed atoms occurs below about $200^{\circ} \mathrm{C}$ (1), while its limited capacity to effect this adsorption at higher temperatures is assumed to result from the thermal promotion of electrons from the $5 d$ to the $6 s$ level (2), with the creation thereby of unpaired $d$-electrons. Even then the concentration of adsorbed hydrogen atoms is small, and would be quite insufficient to sustain a useful catalytic process.

It is possible to increase the concentration of adsorbed hydrogen atoms by providing them in a form other than molecular hydrogen. Gold will chemisorb hydrogen atoms generated in the gas phase by an electrical discharge (3) and hydrogen atoms which have migrated to a gold surface from some adjacent palladium (4). It is then possible to use this adsorbed hydrogen to hydrogenate an olefin (4). Similarly olefins can be hydrogenated by hydrogen atoms obtained by electrochemical discharge of protons at a gold surface (5). Furthermore formic acid may be decomposed on gold (6) and the resulting hydrogen atoms can react with a hydrogen acceptor; if this is oxygen, gold would be acting as an oxidative dehydrogenation catalyst (7). However, the literature presents no evidence that gold can interact with molecular hydrogen below $200^{\circ} \mathrm{C}$ sufficientiy to allow it to act as an efficient catalyst for the hydrogenation of unsaturated substances.

\section{The Preparation of Active Gold Catalysts}

One method of preparing supported metal catalysts is to impregnate a porous inert solid with an aqueous solution of a metal salt, to dry the product and then to reduce it in hydrogen at a suitably high temperature. We have used this impregnation technique to prepare gold supported on silica, on $\gamma$-alumina and on boehmite (aluminium oxyhydroxide, $\mathrm{AlO}(\mathrm{OH})$ ).

Each support was impregnated with an aqueous solution of Specpure chloroauric acid, obtained from Johnson Matthey Chemicals Ltd, and containing sufficient gold to produce catalysts having gold concentrations between 0.01 and 5 weight per cent. These materials were then dried in air at 110 to $130^{\circ} \mathrm{C}$, the heating being continued for 48 hours. Providing the gold concentration was below a critical value $(0.25$ per cent for silica, 5 per cent for $\gamma$-alumina and boehmite), the yellow chloroauric acid decomposed under these conditions to give a mauve-coloured product, illustrated in Figures 1a and $1 \mathrm{~b}$. This mauve colour, typical of gold in a colloidal state, increased in intensity with increasing gold concentration. These catalysts required no further reduction to render them active, and we therefore believe that the product of the thermal decomposition of chloroauric acid is colloidal gold.

Catalysts containing concentrations of gold at or above the critical values mentioned above did not, however, undergo this thermal decomposition, and they required treatment in hydrogen at 100 to $250^{\circ} \mathrm{C}$ to produce metallic gold; they were then dark red or brown in colour, as shown in Figure lc. It is not easy to understand why chloroauric acid on silica decomposes only when present in low concentration. By analogy with the behaviour of chloroplatinic acid on silica (9) one might speculate that the size of chloroauric acid particles formed in the pores of the silica on drying increases with increasing gold concentration, and that smaller particles decompose more easily than large ones. Some difficulty has been experienced in reproducing precisely the activity of gold on silica catalysts; this is probably because we do not yet have a sufficiently good understanding of 


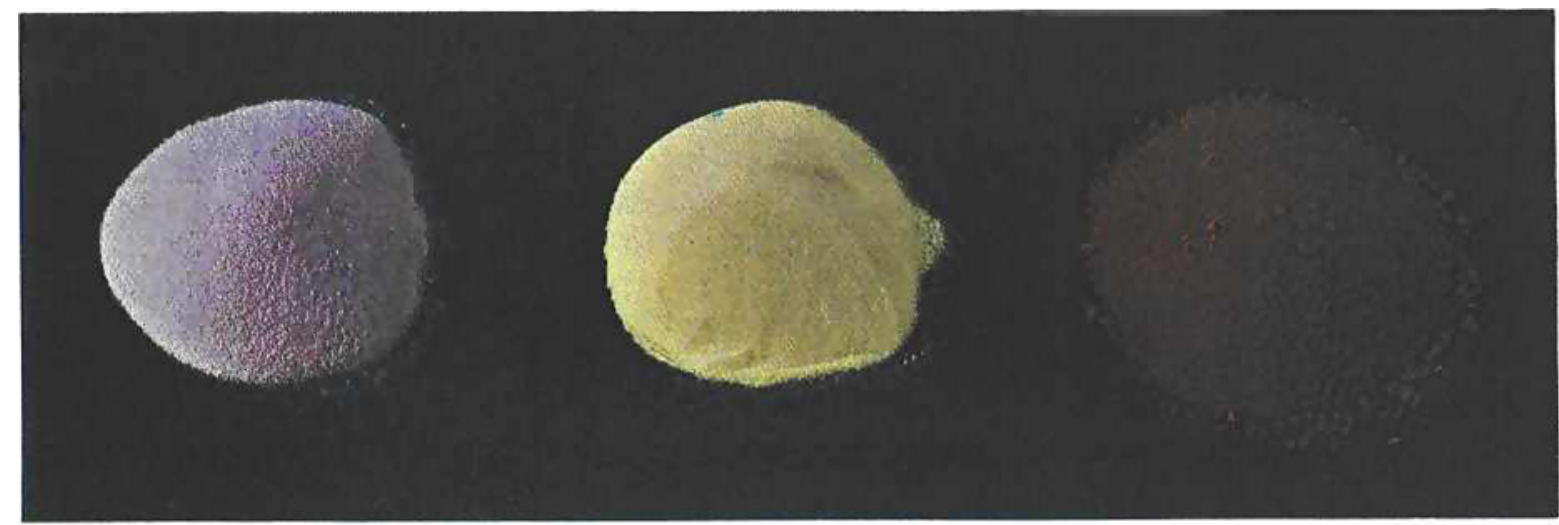

(a)

(b)

(c)

Fig. 1. The brightly coloured products of the reaction of chloroauric acid upon silica. (a) Product obtained after heating material containing $0.05 \%$ gold in air at $120^{\circ} \mathrm{C}$ for $48 \mathrm{~h}$; decomposition to metallic gold has occurred. (b) Product obtained after heating material containing $1.25 \%$ gold under the same conditions; no decomposition has taken place. (c) Product after reducing material containing $5 \%$ gold in hydrogen at $250^{\circ} \mathrm{C}$

all the parameters determining the decomposition of chloroauric acid and further investigation is required to define them adequately.

The preparation of active gold catalysts by thermal decomposition of chloroauric acid was discovered independently by Dr. Geoffrey Webb of Glasgow University, with whom we have collaborated closely in the later stages of our work.

\section{The Hydrogenation and Isomerisation of Olefins}

The activity of small samples of supported gold catalysts was investigated in a continuous flow reactor (10). The reaction selected for study was the hydrogenation of 1-pentene to $n$-pentane, and its simultaneous double-bond migration to the two isomers of 2-pentene (Figure 2). To facilitate observation of the activity, a low partial pressure (1.2 torr) of 1-pentene was used, and a high partial pressure of hydrogen ( $\sim 759$ torr): the total flow rate was $10 \mathrm{ml} / \mathrm{min}$, and the temperature was $100^{\circ} \mathrm{C}$. Products were analysed by gas chromatography.

We immediately observed that silica-supported gold catalysts were active for the hydrogenation of

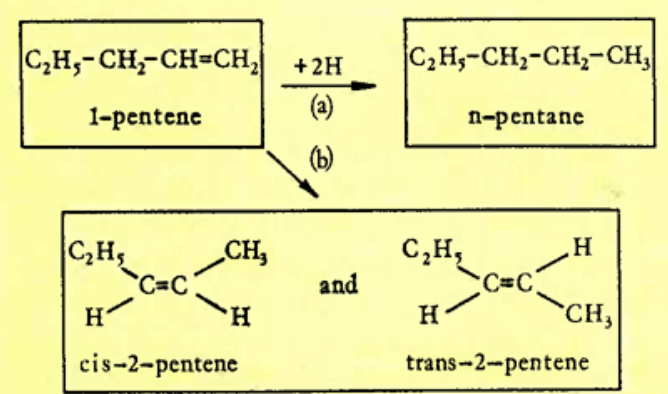

Fig. 2. The hydrogenation (a) and double-bond migration (b) of 1-pentene 1-pentene, but that their activity decreased slowly with time, as shown, for example, in Figure 3, due probably to the deposition of carbonaceous residues on the surface. This decline in activity was not observed when $\gamma$-alumina or boehmite was the support. Conversions measured 60 minutes after the start of the reaction are plotted against gold concentration in Figure 4. The conversions of 1-pentene to $n$-pentane are of course smaller than those which would be observed under the same conditions with comparable catalysts of the platinum group metals, but in view of the fact that no one has ever previously detected any activity at all for gold in olefin hydrogenation we are more than content to have discovered a modest activity.

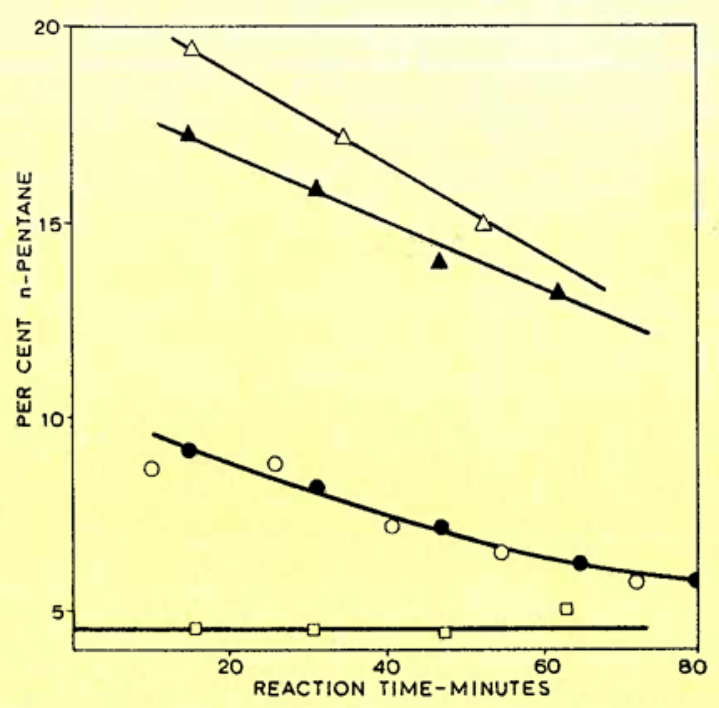

Fig. 3. Hydrogenation activity of $0.2 \mathrm{~g}$ samples of $5 \%$ gold on silica $(\Delta, \Delta), 0.05 \%$ gold on silica $(0, \bullet)$ and $5 \%$ gold on $\gamma$-alumina $(\square)$ under the experimental conditions described in the text 


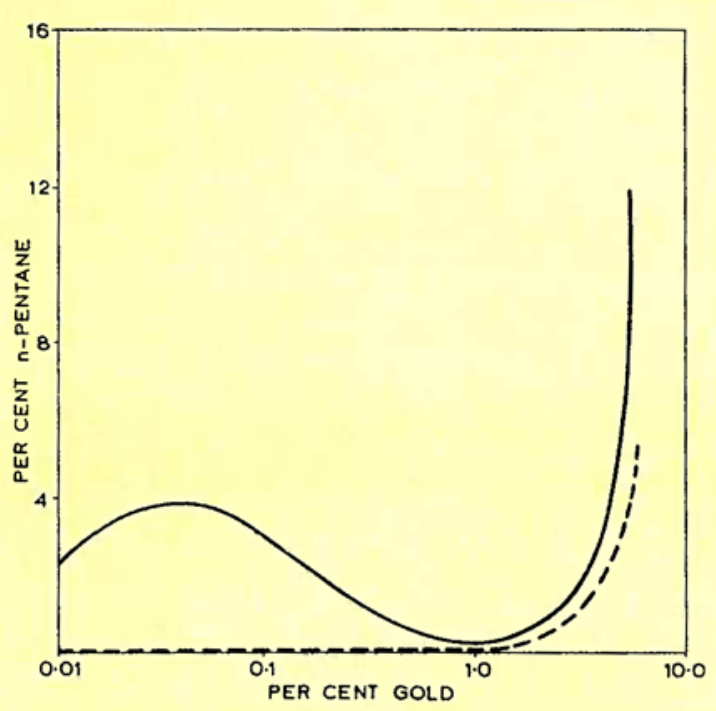

Fig. 4. Activity after 60 minutes of gold on silica $(-)$ and on $\gamma$-alumina (--) for 1-pentene hydrogenation, as a function of gold concentration

Figure 4 demonstrates for gold on silica a remarkable and novel dependence of catalytic activity on metal concentration. Activity is quite high at 5 per cent gold, is markedly lower at 1.25 and 0.5 per cent gold, but increases to higher values at 0.05 and 0.01 per cent gold. In this last respect this catalyst appears to be quite unique. This variation of activity with metal concentration is shown even more vividly when expressed per unit weight of gold as in Figure 5: the apparent turnover number, defined as the number of molecules of 1-pentene hydrogenated per gold atom in unit time, is more than 7000 times greater for 0.01 per cent gold on silica than for 1.25 per cent gold on silica. Very low activities were observed with gold on $\gamma$-alumina with less than 5 per cent gold as seen in Figure 3.

Double-bond migration normally accompanies olefin hydrogenation on metal catalysts, although the ratio of the two rates can vary considerably. It is therefore interesting to note that, with catalysts containing less than 5 per cent gold, no double-bond migration at all was detected: $n$-pentane was the only product observed, and in this respect also gold appears to be a unique metal. One possible area of practical application where this property would be valuable is in the hydrogenation of animal and vegetable oils to produce edible fats, where isomerised products are preferably absent.

Dr. Webb has observed that 1 per cent gold on $\gamma$-alumina or boehmite catalyses the hydrogenation of 1,3-butadiene $\left(\mathrm{CH}_{2}=\mathrm{CH}-\mathrm{CH}=\mathrm{CH}_{2}\right)$ and of 2butyne $\left(\mathrm{CH}_{3}-\mathrm{C} \equiv \mathrm{CH}_{3}\right)$, although at somewhat higher temperatures than those we have used. Dr.
Peter Wells of Hull University, using a 5 per cent gold on silica catalyst supplied by us, has been able to follow the reaction of ethylene with deuterium at 90 and $175^{\circ} \mathrm{C}$, and has found that the distribution of deuterated ethylenes and ethanes closely resembles that observed for platinum on alumina at $175^{\circ} \mathrm{C}(11)$.

\section{The Nature of the Active Centres}

Spectrographic analysis of the chloroauric acid by the suppliers revealed the presence of no significant impurities, and we therefore believe that the properties described above are truly characteristic of gold. Since gold has not previously been reported to have activity in the reaction we have used, what if anything is so special about the preparative method we have used? What kind of active centres exist in these catalysts?

Two alternative hypotheses have suggested themselves. We know that defects produced in gold by cold working exhance its activity in the decomposition of hydrogen peroxide (12). It is possible that, by forming the metal at a lower temperature than is normally used in catalyst preparation, we have produced highly defective gold particles and that surface defects are the centres of catalytic activity. It is, however, uncertain whether they have sufficient thermal stability to account for continuing catalytic phenomena (12).

An alternative possibility is that activity is due to gold crystallites so small that their catalytic properties differ significantly from those of bulk metal (13, 14). Surprisingly, however, study of 5 per cent gold on silica by transmission electron microscopy and by $\mathrm{X}$-ray line broadening indicated the presence of particles in the range 20 to $1000 \AA$; catalysts with lower gold concentrations contained particles as large as $500 \AA$, and we did not observe the decrease of average particle size with decreasing gold concentration expected by analogy with platinum on

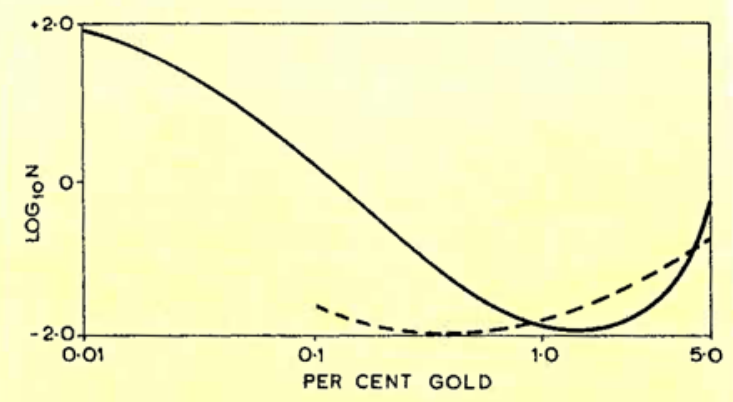

Fig. 5. Dependence of turnover number $N$ on gold concentration for gold on silica (-) and on $\gamma$-alumina $(---)$. ( $N$ is the number of pentane molecules $\times 10^{-5}$ formed per second per gold atom after 60 minutes reaction) 
silica (9). The possibility remains that catalytic activity is due to very small gold particles which could not be sensed by the techniques we employed. Incidentally, the range of gold particle sizes that we have observed encompasses that in which colloid gold is blue in colour (8); particles larger than about $200 \AA$ usually appear red, and the mauve colour of our catalysts is consistent with the presence of particles both greater and smaller than this value.

\section{Transmutation of Catalytic Properties}

We have seen that the catalytic properties of gold as revealed by our work resemble somewhat those of platinum. If the postulate that these properties are due to very small gold particles is correct, then it means we can alter the catalytic activity and specificity of metals simply by changing their crystallite size. Other evidence supports this idea. Very small platinum particles containing only six atoms contained in a zeolite cage behave more like iridium in some reactions of hydrocarbons (13), and the activity of palladium in a zeolite resembles that expected for rhodium in hydrogenation of benzene (14). The explanation proposed is that very small supported metal crystallites become electron deficient, and hence electronically similar to the metal to their left in the Periodic Table, by donation of electrons from metal to the support. Thus sufficiently small particles may have their catalytic properties transmuted, so that gold resembles platinum, platinum resembles iridium and palladium resembles rhodium. Since catalysis, like politics, is 'the art of the possible' (15), and since evidence for transmutation exists, much more attention should be given to the study of the catalytic potentiality of gold, a subject which has lain dormant for so long.

\section{References}

1 R. J. Mikovsky, M. Boudart and H. S. Taylor, f. Am. Chem. Soc., 1954, 76, 3814

2 M. Boudart and L. D. Ptak, 7. Catalysis, 1970, 16, 90; D. D. Eley and D. R. Rossington, "Chemisorption", ed. W. E. Garner, Butterworths (London), 1957, 137. R. P. Chambers and M. Boudart, $\mathcal{F}$. Catalysis, 1966, 5, R. $P$.

3 B. M. W. Trapnell, Proc. Roy. Soc., 1953, A218, 566; R. Culver, J. Pritchard and F. Tompkins, Proc. 2nd Internat. Congress Surface Activity, 1957, 2, 243; H. Wise and K. M. Sancier, $\mathscr{F}$. Catalysis, 1963, 2, 149

4 B. J. Wood and H. Wise, 7 . Catalysis, 1966, 5, 135 ; R. S. Yolles, B. J. Wood and H. Wise, $\mathcal{F}$. Catalysis, 1971 , 21, 66

5 M. Byrne and A. T. Kuhn, F. Chem. Soc. Faraday I, 1972681898

6 W. M. H. Sachtler and N. H. de Boer, F. Phys. Chem., $1960,64,1579$; W. M. H. Sachtler and J. Fahrenfort, Actes 2 me Congres Internat. Catalyse, Edn. Technip, Paris, $I, 1961,831$; G. Parravano, 7. Catalysis, 1970, 18, 320

7 R. P. Chambers and M. Boudart, $\mathcal{F}$. Catalysis, 1966, 5, 517; G. C. Bond, Gold Bull., 1972, 5, (1), 11

$8 \mathrm{~J}$. Turkevich, J. Hillier and P. C. Stevenson, Disc. Faraday Soc., 1951, 11, 55

9 T. A. Dorling, C. J. Burlance and R. L. Moss, $\mathcal{F}$. Catalysis, 1968, 12, 207

10 G. C. Bond, P. A. Sermon, G. Webb, D. A. Buchanan and P. B. Wells F. Chem. Soc., Chem. Comm., 1973, 444

11 G. C. Bond, J. J. Phillipson, P. B. Wells and J. M. Winterbottom, Trans. Faraday Soc., 1964, 60, 1847

12 S. Kishimoto and N. Migaki, F. Phys. Chem., 76, (13), 1907; G. C. Bond, Gold Bull., 1972, 5, (4), 89

13 R. A. Dalla Betta and M. Boudart, Proc. 5th Internat. Congress Catalysis 1972, 1329

14 F. Figueras, R. Gomez and M. Primet, Paper presented at 3rd Internat. Conf. Molecular Sieves, September, 1973

15 D. A. Dowden, Lecture to Society of Chemical Industry in London, 1973

\section{Selecting Gold Pastes for Thick Film Circuits}

Hybrid integrated circuits produced by the thick film process are relatively inexpensive to make and have achieved remarkable success for a number of years. An account of the technology of the gold and gold alloy pastes that are screen printed and fired on to the ceramic substrates, recently given in this journal by R. G. Finch (1), showed that no one conductor formulation offers all the desirable properties, and that a large number of proprietary compositions has been developed to meet specific requirements.

Many of these pastes have already demonstrated their usefulness in complex multi-layer interconnection arrays, but others have not yet been available for long enough to establish their capabilities.

Successful multi-layer fabrication is, however, critically dependent upon the selection of an appropriate conductor paste in combination with a dielectric paste, and a useful study of this problem has been reported in a joint paper by Karel Kurzweil, of Société Honeywell Bull, and James Loughran, of General Electric (2). Specially designed test panels were pre- pared so as to simulate as closely as possible actual multi-layer material and processing conditions and their performance data were established over a range of conductor compositions and dielectrics, the main objective being to find a dependable combination for processing moderate quantities of arrays.

Although the investigation disclosed some properties of both gold conductors and dielectrics that were less than ideal, it did yield a good working combination. The conductivity of a number of gold preparations was found to be quite adequate, approaching that of the bulk metal, while their rheology was also acceptable. Because of its ease of printing, high conductivity, good resolution and compatibility with most dielectrics, a product identified as EMCA $212 \mathrm{~B}$ gold was selected as the most satisfactory and reliable.

\section{References}

1 R. G. Finch, Gold Bulletin, 1972, 5, (2), 26

2 K. Kurzweil and J. Loughran, Solid State Technol., 1973, 16, (5), 36 